\title{
The Third Party Logistics Partner Selection of B2C
}

\section{E-Commerce Enterprise}

\author{
Wei $\mathrm{Xu}^{1}$ and Bing $\mathrm{Li}^{1}$ \\ ${ }^{1}$ School of Management Engineering, Zhengzhou University, Zhengzhou 450001, China
}

\begin{abstract}
In recent years, with the rapid development of Internet, e-commerce enterprises in China is at an alarming rate of sustainable development, the $\mathrm{B} 2 \mathrm{C}$ e-commerce in the online shopping market accounted for a large proportion, with the rapid change of the market and customer needs to establish a flexible distribution service is one of the many e-commerce companies need to solve. Using self logistics capital occupancy bigger; the logistics alliance, with the risk of internal information disclosure; and on the third party logistics, not only capital and manpower can be effectively used, helps enterprises to strengthen the core business. Therefore, it is very important to choose the appropriate third party logistics providers to reduce operating costs and improve the market influence. This paper analyses the existing problems in the third party logistics, the establishment of a more complete index system, according to the actual situation of the suppliers, using the improved AHP method and the entropy coefficient method to get the comprehensive weight, finally get the approximation method to meet the business requirements of the logistics service providers use the ideal, for commercial enterprises to third party logistics service provider selection and puts forward some available models.
\end{abstract}

\section{Introduction}

Ai Rui Advisory data show that in 2015 China's online shopping market B2C transactions reached 1588.2 million, the proportion of the overall online shopping market transactions reached $45.8 \%$, from the growth point of view, in 2015 China's shopping B2C market growth of $68.7 \%$, visible, B2C market in the entire online shopping market and the rapid development of the dominant position [1]. Among them, the logistics is the guarantee of electronic commerce, the first, logistics guarantee production. Second, logistics service provider. At present, there are two forms of e-commerce logistics system, which are self built logistics and outsourcing logistics.

However, for most of the electricity supplier companies, a self built logistics system is very difficult, especially for emerging enterprises, only rely on their own strength is difficult to get through the logistics channel to occupy the market in the short term, in comparison, the third party logistics has a professional, all-round, multi-functional characteristics, can be better to adapt to the business enterprise distribution requirements, improve the level of comprehensive strength of the enterprise. However, there are more and more problems in the third party logistics service.

This requires enterprises to choose the best supplier for the problem of distribution service, reduce operating costs, to help enterprises to achieve the fastest, best service to meet the needs . 


\section{Research status}

Based on the reference to many documents, through the evaluation system of supplier selection and supplier from two aspects proposed third party logistics supplier selection research in the field of more representative studies.

\subsection{Research status of supplier evaluation system and method}

Dickson is the founder of the research on supplier evaluation system, 23 supplier evaluation criteria given by him, and the evaluation index is divided into four grades, are extremely important, more important, important and less important, and pointed out that the quality factor is extremely important [2].

Johnson through the evaluation method of candidate enterprises, it is concluded that four important factors, delivery time, service, cost and quality are the choice of suppliers [3]. Ma Shihua, Lin Yong, the third party logistics service provider evaluation index system is divided into four parts, the quality system, enterprise performance, business structure and production capacity and business environment [4]. Liu Yiyong Sun Shudong, Ma Xuefen, Wu Xiuli put the development potential of the enterprise, logistics technology, equipment status and the service quality of the enterprise as the main factors of the evaluation index system [5] . Yan Xiuxia studied other third party logistics service provider selection of multi objective decision [6] .Zhao Xiaoyu,etc. which using fuzzy comprehensive evaluation method to evaluate the core enterprise, and ranking the importance of the core business, the design of the supply chain is the use of multi objective integer programming model [7] . Liu Gang put forward the supplier value - the supplier evaluation index system of supply risk, and use the entropy weight coefficient method to determine the index weight [8].

Chen Hangjuan, Lu Zhigang put forward the multi attribute decision making method of information entropy to determine the weight of each attribute [9].

At present, the choice of the third party logistics supplier is relatively mature in terms of evaluation system and selection method, but there are still some shortcomings. In the evaluation system, the former suppliers often pay more attention to some of the static indicators such as quality, price and ignore the customer's personalized and diversity requirements. On the choice of methods, qualitative methods such as Delphy. expert results will be influenced by subjective factors; quantitative methods such as purchasing cost method, although this method only needs to compare the supplier's quotation, and choosing a lower price supplier, looking simple but there is a big risk.

\subsection{Establishment and research method of index system of this paper}

Based on the index system, not only retains some of the traditional static indicators such as quality, price, these aspects such as the flexible delivery of the supplier, the prospects for the development of suppliers, the establishment of information capacity are also conclude to form more complete supplier evaluation system. In the research methods, this paper is not using a single research method, using the improved AHP and entropy coefficient method combined weight, and proposing TOPSIS comprehensive evaluation model.

This combination of qualitative and quantitative methods, both the advantages of a single method and to make up for the disadvantages of a single method, so that the research process is more abundant and comprehensive. However, each index weight is the key issue of the study, in order to solve this problem, this paper use the subjective and objective weighting method, proposing AHP and entropy coefficient method improved comprehensive weight, this method is effective to combine the two kinds of weight information, which fully use the objective information, and achieve the greatest possible of the decision-maker's subjective intention. Finally, the TOPSIS model is used to find the satisfactory solutions.

\section{B2C e-commerce enterprise 3 party logistics supplier evaluation index system}




\subsection{B2C e-commerce enterprise development status quo}

With the continuous development of network shopping market the proportion of B2C e-commerce market in the online shopping market is more and more comprehensive, in order to explain this question, this article illustrate these two aspects the $\mathrm{B} 2 \mathrm{C}$ e-commerce market scale and market share in detail.

\subsection{1 e-commerce market scale}

In 2015 the network shopping market share of $22.9 \%$ in the entire e-commerce market segment.B2C market share trading volume in the online shopping market is a sharp increase in the recent six years survey, in 2011 B2C accounted for the first time exceeded $20 \%$, accounting for $29.7 \%$ in 2012,in 2013 accounted for $35.1 \%$,and in 2015 B2C market transactions accounted for $45.8 \%$ of the entire online shopping market. In just a few years, the $\mathrm{B} 2 \mathrm{C}$ market in the entire online shopping market develops rapidly and gradually holds the dominant position.

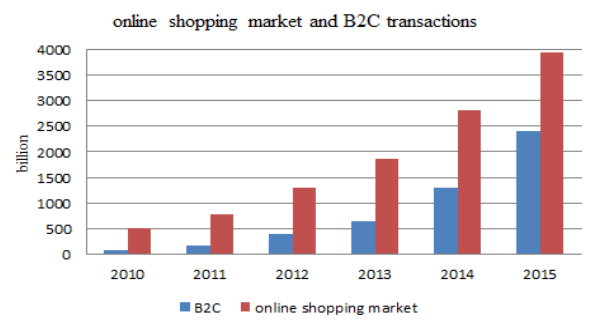

Fig. 1. Caption of the Figure 1. Below the figure.

\subsubsection{Market share}

According to the survey, with the B2C market demand, B2C shopping sites are also increasing, which are familiar with the Jing dong, such as $\mathrm{T}$ mall, suning.com plays an important role in the whole B2C market, in 2015 the scale of the market share of B2C shopping website transactions in China see Figure 2.

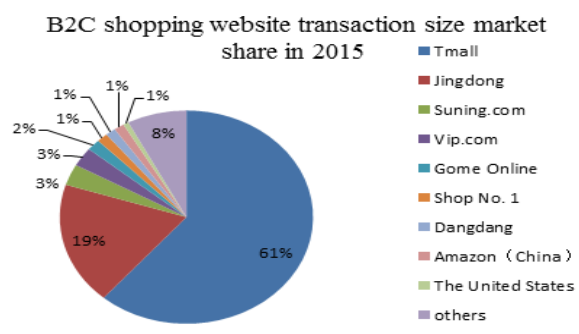

Fig. 2. Caption of the Figure 2. Below the figure.

From the above illustrations, it can see that the $\mathrm{B} 2 \mathrm{C}$ market with the rapid pace of development gradually becomes the main driving force of the online shopping market.

\subsection{Analysis in factors of supplier selection}

Based on the above third party logistics development situation, analysing the factors that affect the supplier selection, among them, the third party logistics service provider is the focus of our research, this paper will analyze the following factors.

(1) third party logistics service quality 
Third party logistics service quality is the most important factor that should be considered when selecting suppliers, the quality of service will directly affect the reputation of enterprises.

(2) the cost of third party logistics service

cost of logistics service is too high has been an important factor affecting domestic logistics development, enterprises in the selection of third party logistics, reduce the logistics cost of service must follow the principle of logistics service cost will directly determine the cost of enterprises so that this paper will treat the service cost as an important factor.

(3) service of the geographical Scope

The third party logistics provider selection should be consistent with the scope of business enterprise principle, for large multinational companies, its scope of business throughout the world, its sales is bound to be about local culture or influence, in order to further develop the market to help the choice of local suppliers.

(4) third party logistics flexibility

In the network economy environment, customers pay attention to the ability to adapt to rapid changes in the market and customer demand diversification so that logistics flexibility, time flexibility dynamic index is also equally important therefore, the flexible factors, the third party logistics is an indispensable factor.

(5) service provider information sharing ability

B2C enterprises and logistics providers should also realize information sharing, information ability of logistics providers will directly affect the $\mathrm{B} 2 \mathrm{C}$ enterprise and its information exchange.

\subsection{The establishment of index system of the third party logistics supplier}

This article through to the domestic and foreign related literature retrieval and consulting experts and scholars, finishing induction, and ultimately determine the logistics distribution supplier selection index system, as shown in Figure 3 .

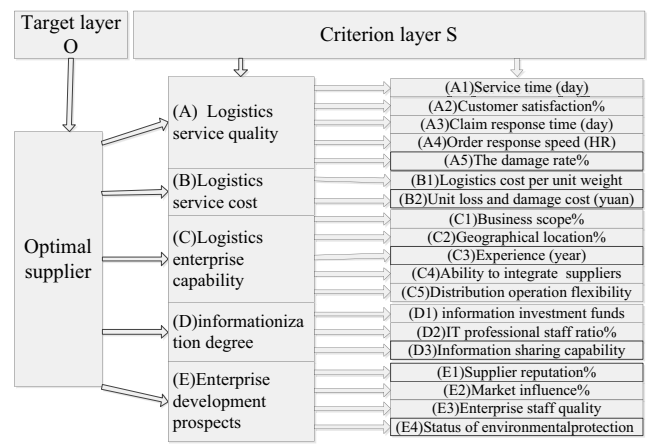

Fig. 3. Caption of the Figure 3. Below the figure.

\section{Model establishment of evaluation and selection of supplier}

\subsection{Improved analytic hierarchy process to determine subjective weights}

The traditional AHP method to construct the judgment matrix A, calculate feature vector, to obtain the maximum eigenvalue, but often in the next consistency check is especially cumbersome, because in practice, consistency is not satisfied, with most estimates to adjust the judgment matrix, it is possible to adjust one or not to meet the requirements, with a lot of blindness [10]. This article in order to avoid this kind of blindness, the use of the concept of the optimal transfer matrix, so that the judgment matrix nature to meet the consistency requirements. Steps are as follows.

constructing judgment matrix A 
Construct judgment matrix to use of the double factors, determine the degree of importance, the rule layer $\mathrm{S}$ and sub rule layer $\mathrm{S}_{\mathrm{ij}}$ to construct the judgment matrix in this paper respectively.

construct the anti symmetric matrix B

From above, $\mathrm{A}$ is Reciprocal matrix, that is $a_{i j}=1 / a_{j i}, \quad B=\lg A$, that is $b_{i j}=\lg a_{i j}=\lg \frac{1}{a_{i j}}=-b_{j i}$, $\mathrm{B}$ is the structure of the anti symmetric matrix.

Calculation of the optimal transfer matrix $\mathrm{C}$

If $\mathrm{C}$ is the transfer matrix, $\mathrm{B}$ is the anti symmetric matrix and $\sum_{i}^{n} \sum_{j}^{n}\left(c_{i j}-b_{i j}\right)^{2}$ is the minimum, it can say that $\mathrm{C}$ is the optimal transfer matrix for $\mathrm{B}, c_{i j}=\frac{1}{n} \sum_{k=1}^{n}\left(b_{i k}-b_{j k}\right)$.

To calculate the quasi optimal consistent matrix of $\mathrm{A}^{*}$

From $\mathrm{A}^{*}=10^{\mathrm{C}}$, that is $a_{i j}=10^{c_{i j}}=10^{\frac{1}{n} \sum_{k=1}^{n}\left(b_{k}-b_{j k}\right)}=\frac{a_{i k}}{b_{j k}}$, by the definition of A is the reciprocal matrix, if $a_{i j}=\frac{a_{i j}}{b_{j k}}$, that A is consistent. From the above, $\mathrm{A}^{*}$ as a quasi optimal consistent matrix

To determine the feature vector by extract method

$\mathrm{A}^{*}$ will be matrix elements in line multiplication, $\mathrm{n}$ times of the product, do get normalized, $w^{\prime}=\left[W_{1}, W_{2}, W_{3},, w_{n}\right]^{T}$ as the feature vectors .

Using the above steps, it can get the supplier's final subjective weight vector $w_{1}=\left[w_{1 l}, w_{2 l}, w_{3 l},, w_{n l}\right]^{T}$

\section{2 improved entropy coefficient method to determine the objective weight}

For the objective weight model more reasonable should be.the objective weight of the model obtained can not only reflect the information of the decision matrix and decision matrix; when the change, change degree of weight should be and the decision matrix changes. Therefore, in order to overcome the above problems, in this paper, based on the traditional entropy model, a flexible entropy coefficient model is established, and the specific steps are as follows.

(1) Structural decision matrix D

Order $\mathrm{Y}=\left(y_{i j}\right)$, beside, $y_{i j}=\frac{x_{i j}}{\sqrt{\sum_{i=1}^{m} x_{i j}^{2}}}$, standardized matrix normalization process is $D=\left(D_{i j}\right)_{m \times n}$.

$$
\begin{gathered}
d_{i j}=\frac{y_{i j}}{y_{j}^{\max }}, j \in J_{1} \\
d_{i j}=\frac{y_{j}^{\min }}{y_{i j}}, j \in J_{2} \\
y_{j}^{\max }=\max \left(y_{1 j}, y_{2 j}, y_{3 j},,, y_{m j}\right), j=1,2,3,,, n \\
y_{j}^{\min }=\min \left(y_{1 j}, y_{2 j}, y_{3 j},,, y_{m j}\right), j=1,2,3,,, n
\end{gathered}
$$

(2) Entropy coefficient model 
For the normalized matrix $\mathrm{D}$, the entropy of the first $\mathrm{j}$ attribute is defined as $h_{j}=\rho-E_{j}, E_{j}=-\sum_{i}^{n} d_{i j} \frac{\ln d_{i j}}{\ln n}$. Then the entropy coefficient model used to solve the objective weight is $\min =w^{T} k w$, s.t. $e^{T} w=1, w \geq 0$. Lagrange number multiplication.

order $L=w^{T} k w-\lambda\left(e^{T} w-1\right)$, it can get the objective weight $w=w_{2}=\frac{k^{-1} e}{e^{T} k^{-1} e}$. From the above, the comprehensive weight is $w_{j}=\frac{w_{1 j} \times w_{2 j}}{\sum_{j=1}^{n} w_{1 j} \times w_{2 j}}$.

\section{3 the TOPSIS method to build the choice of third party logistics service providers evaluation}

TOPSIS model is a classical multi-objective decision-making method. Using the ideal approach, it should first construct the ideal and negative ideal solution, by calculating the ideal solution and negative solution of the Euclidean distance between each scheme and ideal scheme, and obtained the various positive and negative ideal solution close to the degree of closeness to the ideal for the supplier; and understanding recently and negative ideal solution the most distant scheme is the solution satisfactory solution. The specific steps are as follows.

(1) Weighted normalized matrix v

$$
v=\left(v_{i j}\right)_{m \times n}=\left(w_{j} y_{i j}\right)_{m \times n}=\left[\begin{array}{cccc}
v_{11} & v_{12} & \ldots & v_{1 n} \\
v_{21} & v_{22} & \ldots & v_{2 n} \\
\ldots & \ldots & \ldots & \ldots \\
v_{m 1} & v_{m 2} & \ldots & v_{m n}
\end{array}\right]
$$

(2) determine the positive ideal solution $\mathrm{v}^{+}$and negative ideal solution $\mathrm{v}^{-}$

$$
\begin{aligned}
& v^{+}=\left\{\begin{array}{lll}
v_{1}^{+}, & v_{2}^{+}, \quad, \quad v_{m}^{+}
\end{array}\right\}=\left\{\max _{1 \leq i \leq m} v_{i j}\left|j \in J_{1}, \min _{1 \leq i \leq m} v_{i j}\right| j \in J_{2},\right\} \\
& v^{-}=\left\{v_{1}^{-}, v_{2}^{-}, \quad, \quad v_{m}^{-}\right\}=\left\{\min _{1 \leq i \leq m} v_{i j}\left|j \in J_{1}, \max _{1 \leq i \leq m} v_{i j}\right| j \in J_{2},\right\}
\end{aligned}
$$

(3)Calculate the Euclidean distance and the relative closeness degree and order

The evaluation value of logistics supplier is the distance from the positive ideal solution and the negative ideal solution.

$$
S_{i}^{+}=\sqrt{\sum_{j}^{n}\left(v_{i j}-v_{j}^{+}\right)^{2}}, i=1,2,,, m S_{i}^{-}=\sqrt{\sum_{j}^{n}\left(v_{i j}-v_{j}^{-}\right)^{2}}, i=1,2,,, m
$$

The evaluation value of logistics supplier is the distance from the positive ideal solution and the negative ideal solution $C_{i}^{*}=\frac{S_{i}^{-}}{S_{i}^{+}+S_{i}^{-}}, i=1,2,,, m$

By the relative size of the progress of the paste to judge the merits of the supplier, close to a large degree of satisfaction is the best supplier.

\section{5 case study analysis}

\subsection{Case introduction}


There is a B2C e-commerce business clothing, food, daily necessities and other products, since its inception, in the principle of maximizing the interests of customers, quickly become one of the most influential $\mathrm{B} 2 \mathrm{C}$ e-commerce business. The company originally only in the first tier cities such as Guangzhou, Shanghai and other implementation of door-to-door, but with the market and customer demand. The B2C e-commerce enterprises have opened the second tier cities of logistics and distribution services, however, the original logistics services have been unable to meet the needs of enterprises. After screening 5 logistics suppliers have become the candidate supplier, respectively A, B, C, D, E said, according to the above proposed evaluation index system and the logistics supplier performance in the previous situation, combined with the actual operating results of enterprises and related experts. The evaluation values of the 5 suppliers are as shown in Table 1.

Table 1. Candidate supplier index evaluation form.

\begin{tabular}{|c|c|c|c|c|c|}
\hline \multirow{2}{*}{$\begin{array}{l}\text { evaluating } \\
\text { indicator }\end{array}$} & \multicolumn{5}{|c|}{ Distributor candidates } \\
\hline & A & B & $\mathrm{C}$ & $\mathrm{D}$ & $\mathrm{E}$ \\
\hline $\mathrm{A} 1$ & 5 & 3 & 5 & 4 & 6 \\
\hline $\mathrm{A} 2$ & 65.6 & 70.5 & 68.9 & 78.9 & 58.3 \\
\hline A3 & 2 & 3 & 2 & 1 & 1 \\
\hline A4 & 24 & 6 & 18 & 12 & 24 \\
\hline A5 & 3.6 & 5.3 & 4.5 & 2.8 & 3.2 \\
\hline $\mathrm{B} 1$ & 26 & 18 & 29 & 15 & 20 \\
\hline $\mathrm{B} 2$ & 0.021 & 0.036 & 0.052 & 0.018 & 0.046 \\
\hline $\mathrm{C} 1$ & 80.2 & 78.8 & 85.6 & 76.3 & 89.1 \\
\hline $\mathrm{C} 2$ & 69.1 & 76.5 & 80.6 & 86.2 & 72.9 \\
\hline C3 & 12 & 8 & 6 & 10 & 15 \\
\hline $\mathrm{C} 4$ & 76.4 & 68.1 & 80.6 & 79.3 & 70.8 \\
\hline $\mathrm{C5}$ & 72.8 & 86.5 & 88.6 & 78.2 & 63.4 \\
\hline D1 & 150 & 320 & 460 & 510 & 600 \\
\hline D2 & 16.8 & 20.1 & 25.6 & 19.7 & 22.4 \\
\hline D3 & 5 & 4 & 3 & 5 & 4 \\
\hline E1 & 82.4 & 78.6 & 80.7 & 79.8 & 83.9 \\
\hline E2 & 16.7 & 10.3 & 9.8 & 12.1 & 18.9 \\
\hline E3 & 81.2 & 85.8 & 69.6 & 78.5 & 86.7 \\
\hline E4 & 69.7 & 75.6 & 80.4 & 78.1 & 86.8 \\
\hline
\end{tabular}

\subsection{Supplier selection and comprehensive evaluation}

According to the above evaluation model, the process is as follows.

\subsubsection{Establish the initial decision matrix and standardization}

Initial judgment matrix $\mathrm{X}$ 


$\left[\begin{array}{cccccccccc}5 & 65.5 & 2 & 24 & 3.6 & 26 & 0.021 & 80.2 & 69.1 & 12 \\ 3 & 70.5 & 3 & 6 & 5.3 & 18 & 0.036 & 78.8 & 76.5 & 8 \\ 5 & 68.9 & 2 & 18 & 4.5 & 29 & 0.052 & 85.6 & 80.6 & 6 \\ 4 & 78.9 & 1 & 12 & 2.8 & 15 & 0.018 & 76.3 & 86.2 & 10 \\ 6 & 58.3 & 1 & 24 & 3.2 & 20 & 0.046 & 89.1 & 72.9 & 15 \\ 76.4 & 72.8 & 150 & 16.8 & 5 & 82.4 & 16.7 & 81.2 & 69.7 \\ 68.1 & 86.5 & 320 & 20.1 & 4 & 78.6 & 10.3 & 85.8 & 75.6 \\ 80.6 & 88.6 & 460 & 25.6 & 3 & 80.7 & 9.8 & 69.6 & 80.4 \\ 79.3 & 78.2 & 510 & 19.7 & 5 & 79.8 & 12.1 & 78.5 & 78.1 \\ 70.8 & 63.4 & 600 & 22.4 & 4 & 83.9 & 18.9 & 86.7 & 86.6\end{array}\right]$

Normalized matrix Y

$\left.\begin{array}{llllllllll}0.475 & 0.427 & 0.459 & 0.590 & 0.404 & 0.524 & 0.253 & 0.437 & 0.400 & 0.503 \\ 0.285 & 0.458 & 0.688 & 0.147 & 0.595 & 0.362 & 0.434 & 0.429 & 0.443 & 0.335 \\ 0.475 & 0.448 & 0.459 & 0.442 & 0.505 & 0.584 & 0.627 & 0.466 & 0.252 & 0.479 \\ 0.380 & 0.513 & 0.229 & 0.295 & 0.314 & 0.302 & 0.217 & 0.415 & 0.499 & 0.419 \\ 0.569 & 0.379 & 0.229 & 0.590 & 0.359 & 0.403 & 0.554 & 0.485 & 0.422 & 0.629 \\ 0.454 & 0.415 & 0.153 & 0.356 & 0.524 & 0.454 & 0.532 & 0.451 & 0.398 \\ 0.405 & 0.493 & 0.327 & 0.425 & 0.419 & 0.433 & 0.328 & 0.476 & 0.432 \\ 0.479 & 0.505 & 0.470 & 0.542 & 0.314 & 0.445 & 0.312 & 0.386 & 0.459 \\ 0.472 & 0.446 & 0.521 & 0.417 & 0.524 & 0.440 & 0.386 & 0.436 & 0.446 \\ 0.421 & 0.361 & 0.613 & 0.474 & 0.419 & 0.463 & 0.602 & 0.481 & 0.495\end{array}\right]$

\subsubsection{Determine the weight of indicators}

According to the above requirements to improve the analytic hierarchy process for the subjective weight of the steps, the target layer $\mathrm{S}$ for the target layer $\mathrm{O}$, the corresponding judgment matrix, anti symmetric matrix, the optimal transfer matrix and to be and consistent matrix are as follow.

$$
\left[\begin{array}{ccccccc}
O & S_{1} & S_{2} & S_{3} & S_{4} & S_{5} \\
S_{1} & 0 & 0.477 & 0.602 & 0.778 & 0.699 \\
S_{2} & -0.477 & 0 & 0.699 & 0.602 & 0.778 \\
S_{3} & -0.602 & -0.699 & 0 & 0.301 & 0.477 \\
S_{4} & -0.778 & -0.602 & -0.301 & 0 & 0.602 \\
S_{5} & -0.699 & -0.778 & -0.477 & -0.602 & 0
\end{array}\right]\left[\begin{array}{ccccccc}
O & S_{1} & S_{2} & S_{3} & S_{4} & S_{5} \\
S_{1} & 0 & 0.191 & 0.616 & 0.727 & 1.022 \\
S_{2} & -0.191 & 0 & 0.425 & 0.536 & 0.832 \\
S_{3} & -0.616 & -0.425 & 0 & 0.111 & 0.407 \\
S_{4} & -0.727 & -0.536 & -0.111 & 0 & 0.295 \\
S_{5} & -1.022 & -0.832 & -0.407 & -0.295 & 0
\end{array}\right]\left[\begin{array}{cccccc}
O & S_{1} & S_{2} & S_{3} & S_{4} & S_{5} \\
S_{1} & 1 & 1.552 & 4.130 & 5.333 & 10.52 \\
S_{2} & 0.644 & 1 & 2.661 & 3.436 & 6.792 \\
S_{3} & 0.242 & 0.376 & 1 & 1.291 & 2.551 \\
S_{4} & 0.186 & 0.291 & 0.775 & 1 & 1.972 \\
S_{5} & 0.095 & 0.147 & 0.392 & 0.507 & 1
\end{array}\right]
$$

Using the root method to deal with the quasi and consistent matrix can target on criterion layer relative weights for

Subjective and Objective weight can be.

$w_{1}=[0.138,0.041,0.062,0.059,0.162,0.084,0.198,0.006,0.22,0.041,0.031,0.012,0.026$, $0.005,0.066,0.029,0.011,0.004,0.014]^{\mathrm{T}}$

$w_{2}=[0.032,0.025,0.123,0.234,0.033,0.035,0.078,0.027,0.029,0.046,0.026,0.032,0.106$, $0.028,0.026,0.031,0.11,0.024]^{\mathrm{T}}$

Comprehensive weight can be.

$w=[0.073,0.017,0.123,0.231,0.088,0.049,0.252,0.003,0.11,0.031,0.014,0.007,0.043$, $0.002,0.028,0.003,0.018,0.005,0.002]^{\mathrm{T}}$

\subsubsection{Calculate the weighted normalized matrix $V$}




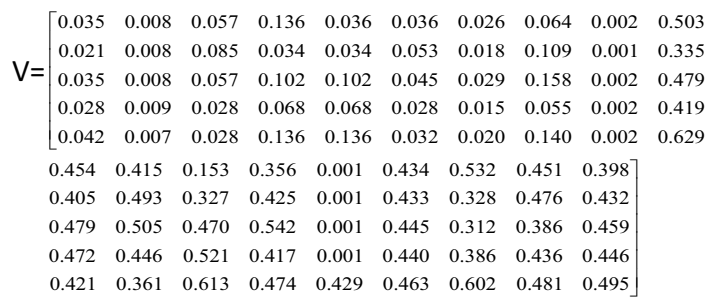

The positive and negative ideal solutions and the European distance between the candidate suppliers and the positive and negative ideal solutions are

$$
\begin{aligned}
& \mathrm{V}^{+}=(0.021,0.009,0.028,0.068,0.028,0.015,0.055,0.002,0.006, \\
& 0.019,0.007,0.004,0.026,0.001,0.015,0.002,0.011,0.003,0.001) \\
& \mathrm{V}^{-}=(0.042,0.007,0.085,0.136,0.053,0.029,0.158,0.001,0.005, \\
& 0.008,0.006,0.003,0.002,0.001,0.009,0.001,0.006,0.002,0.001) \\
& S_{1}^{+}=0.0794, \quad S_{2}^{+}=0.0905, \quad S_{3}^{+}=0.116, \quad S_{4}^{+}=0.0107, \quad S_{5}^{+}=0.1109 \\
& S_{1}^{-}=0.1009, \quad S_{2}^{-}=0.1163, \quad S_{3}^{-}=0.0492, \quad S_{4}^{-}=0.1415, \quad S_{5}^{-}=0.0698
\end{aligned}
$$

The closeness of each candidate supplier is calculated by the formula

$$
C_{1}^{*}=0.560, \quad C_{2}^{*}=0.788, \quad C_{3}^{*}=0.298, \quad C_{4}^{*}=0.93, \quad C_{5}^{*}=0.086
$$

From this, it can see that the supplier D close to the highest degree, is the best partner of $\mathrm{B} 2 \mathrm{C}$ enterprise.

\section{Concluding remarks}

Aiming at the logistics service supplier business problems, establish the index system and determine the weight by using the improved AHP method and the entropy weight coefficient method, and then use the ideal approximation method to calculate the degree of closeness of each supplier, according to the order of suppliers close to the level, select the closest suppliers, is the best partner. Through the design and analysis of the case, it is proved that this method is feasible and effective for the third party logistics supplier selection provides a reference, but this article also has some shortcomings, such as the factor analysis, may not be able to cover all the factors may also change with the times, some new factors will be taken into account. I believe that research in this area will be more comprehensive, more and more mature.

\section{References}

1. Artis M, Krolzig H M, Toro J. The European Business Cycle// the ERM', International Journal of Finance and Economics. (1999).

2. Dickson G.W.An Analysis of Vendor Selection Systems and Decisions . Journal of Purchasing, 2,6(1966).

3. Johnson M.V. Partner Selection in the Agile Environment, Creating the Agile Organization: Models, Metrics and Pilot, 4th Annual conference proceedings, 21,6(1995).

4. Ma Shihua, Lin Yong, Chen Zhixiang. Supply chain management (First Edition) . Beijing: China Machine Press, 2000.

5. Ma Xuefen, Liu Yiyong, Sun Shudong, et al. Evaluation and selection of the three party logistics enterprises under the environment of supply chain management . Computer engineering and applications, 14,3(2003).

6. Yan Xiuxia, Sun Linyan, Luo Bo. Multi objective decision making of third party logistics supplier selection. China mechanical engineering,2004.

7. Zhao Xiaoyu, Huang Xiaoyuan, Sun Wei. Supply chain design method for key suppliers and customers . system engineering, $23,6(2005)$. 
8. Liu Gang. Classification and evaluation of suppliers based on entropy method [J]. Journal of systems management, 19,6(2010).

9. Lu Zhigang, Chen Hangjuan. Fuzzy multiple attribute decision making supplier selection method basedon information entropy. application of computer systems, 18,3(2012).

10. Liu H T, Wang W K. An integrated fuzzy approach for provider evaluation and selection in third-party logistics. 36,3(2009). 